\title{
THE SEASON AND DIURNAL CYCLES OF SURFACE LEVEL REFRACTIVITY ON ELECTROMAGNETIC WAVE PATH IN LAGOS, NIGERIA
}

\author{
J. A. Falade ${ }^{1}$, S. O. Adesanya ${ }^{2}$ \\ ${ }^{1}$ Department of Physical Sciences, Redeemer's University, Ede, Nigeria \\ ${ }^{2}$ Department of Mathematical Sciences, Redeemer's University, Ede, Nigeria
}

The paper is received on June 6, 2018

\begin{abstract}
Data obtained from Nigerian Environmental Climatic Observing Program (NECOP) station located at the University of Lagos, Akoka were employed to study the variation of surface radio refractivity for Lagos. Attention were focused on seasonal variation because the diurnal variation though could be abrupt, but the period of occurrence is short compared to the seasonal variation of the surface refractivity. Most of communication equipment, particularly the digital systems, require short time to transmit information between base stations and mobile devices and also operate near the surface and their paths vary in matter of minutes due to the influence of weather conditions. Lagos is located in a coastal area and is vulnerable to weather fluctuation and hence, a good candidate for localized refractive index fluctuation. The diurnal profile is having the same pattern during the dry and the wet season and is high through the night and drops only slightly in the morning when sun rises to about 14:00h before it picks up slightly again round 16:00h when sun begins to set. The monthly graphs show the real time pattern of the other meteorological parameters and surface refractivity at a particular time of the year and thereby constitute the seasonal variation. The weather pattern and high rainfall in Lagos accounted for high surface radio refractivity throughout the year but goes low only, during the harmattan period which coincides with dry season. The diurnal refractivity distribution is a function of daily weather parameters, while the seasonal variation tilted towards the trends in the climatic conditions of Lagos.
\end{abstract}

Keywords: Inter Tropical Discontinuity, Refractive Index, Coastal area, Radio path. 


\section{Introduction}

A good knowledge of the path of propagation phenomena is required to design appropriate communication systems, such as radar, broadcasting systems, etc. Adverse effects may be caused by fluctuating weather parameters on radio wave propagation path which can produce random variations in the amplitude, phase, frequency, polarization, coherence bandwidth, delay spread, and propagation direction of the electromagnetic waves. With the rapid expansion of wireless communication systems, there has been a considerable increase in the need to study the propagation path of the electromagnetic waves for radio-frequency planning both in terms of link and propagation modelling. Hence, the study of the tropospheric radio refractive index has aroused considerable interest primarily because of its influence on radio-wave communication. The troposphere is the region of the atmosphere where weather phenomena can change within a short period and constituents of weather (temperature, relative humidity and pressure) produces refractive index (RI) which cannot be neglected at frequencies of about $30 \mathrm{MHz}$ and above. A sudden change in RI in a small region within space can scatter radio energy due to inhomogeneity nature of lower atmosphere. In many geographical areas of Nigeria, the inhomogeneities of the surface level of the troposphere are more severe due to heating effect of the ground surface. The non-uniform heating of ground areas produces ascending and descending air currents which results in turbulences and mixing of air masses vertically and this decides the temperature and in turn the variability in weather conditions in the troposphere. Horizontal variation of refractive index is generally negligible in the lower troposphere compared to the large-scale vertical variation, but an horizontally-stratified abrupt changes in RI can cause reflection, while the extended negative gradients can lead to anomalous propagation [1]. In case of coastal areas, the assumption of horizontal stratification of the lower region of the troposphere between small scale and medium scale of turbulences is justified over the coastal areas of Nigeria because of the significant change in climatic condition of the region. 
Apart from inhomogeneity and horizontal stratification in the region, variation in lapse rate will in turn cause variations in surface warming amplification and hence tropospheric temperatures and their variability are more geographically uniform than at the surface level particularly in the tropics [2]. The tropical troposphere cannot maintain substantial horizontal pressure and temperature gradients because the local Coriolis parameter is small. The surface then is less affected by this constraint and instead shows a large range of $\Delta T$, since the land tends to warm more than the Ocean due to processes connected to decreasing relative humidity over land and near constant over Ocean. Gradual variations in the RI result in a bending of the paths taken by radio waves, so that they can follow the curvature of the earth. This can cause the refraction and scattering of electromagnetic waves propagating through the troposphere.

The radio RI at ground level is paramount at a location like Lagos because is surrounded by large bodies of water like rivers and also shearing boundary with Atlantic Ocean. The time varying properties of the atmosphere will determine the level of homogeneities of the medium, in terms of the variation properties of weather and hence the refractive index which affects the propagation of ground waves and also promote communication over large ranges.

The earth's surface is the bottom boundary of the atmosphere and is the mixing region of the atmosphere where meteorological parameters are mostly affected. In order to characterize the surface propagation environment, which is usually heterogeneous in nature due to the boundary layer created in the region. The boundary layer responds rapidly to the large contrasts in surface roughness, moisture and thermal forcing between the land and Sea is called the atmosphere boundary layer $(\mathrm{ABL})$.

The ITU-R had observed that Africa is one of the regions of the world from which little or no data available for the planning of broadcasting services and are such, the propagation mechanisms for such regions are not well understood. The data and curves of tropospheric layer obtained from the measurements performed in other parts of the world such as Europe, Japan, and North America are extrapolating for use 
in such regions. Only few measurements were conducted in Africa before the campaign of International Telecommunication Union- Recommendation (ITU-R) in 1984 and none of the ITU-initiated experiments were mounted or conducted in Nigeria. As of today, not all locations in Nigeria has documented data of meteorological parameters and surprisingly most locations have different climatic conditions at different times of the year. Since radio planning require the studying of locality's climate and the little data available could not explore the diurnal trend of refractivity. As a consequence, there is a lack of understanding of the propagation mechanisms associated with many regions within Nigeria. Earlier radio scientists have studied radio refractivity both in temperate and high latitude regions of the World [3]. In response to the ITU-R's call since 1984 for meteorological data from tropical climatic region (particularly in Africa), only few researchers have contributed to the data base and their contributions are staggered. Other contributors from Africa, particularly from Nigeria for surface refractivity [4-8] and the upper air refractivity [9-10]. With the number of studies mentioned at the surface level only few of them referred to Lagos with different weather pattern from other parts of Nigeria and also commercial city where radio communication without interference is highly required.

Horizontal variation of refractive index is usually assumed to be generally negligible in the lower troposphere compared to the large-scale vertical variation. This is not true in some regions because of physical and geographical features of the region. Horizontal variation of refractive index could be significant in some locations in Nigeria because of the significant change in climatic conditions associated with local or mesoscale meteorological factors. Therefore, the Nigeria radio space is unique and requires direct characterization for different geographical location.

The Centre for Basic Space Science (CBSS) of NASRDA has therefore embarked on propagation data collection from the different climatic zones of Nigeria with the aim of making propagation data bank for use in designing and predicting purposes in order to ensure a qualitative and effective communication system in Nigeria. This work focuses on the current status of propagation data at the ground surface for Lagos $\left(3.35^{\circ} \mathrm{E}, 6.6^{\circ} \mathrm{N}\right)$, a commercial centre in Nigeria through CBSS). 


\section{Climate and Weather Characteristics in Lagos}

The geographical location is swamp forest and share boundary with Atlantic Ocean in the south and also having large bodies of water within. The seasonal northward and southward oscillatory movement of the Inter-Tropical Discontinuity (ITD) dictates the pattern of weather in Lagos like any other parts of Nigeria. There are two seasons in Nigeria but not sharply defined in Lagos, though the two seasons are still recognised. A wet season from April to October, with generally lower temperature, and a dry season from November to March, with temperatures rarely exceed $32^{\circ} \mathrm{C}\left(90^{\circ} \mathrm{F}\right)$, but humidity is very high and nights are sometimes hot.

The moist Southwesterly winds from the South Atlantic Ocean, which is the source of moisture needed for rainfall and thunderstorms usually begin in late February to early March and prevail throughout from February to October. This period is termed rainy season. In reverse manner, the Northeasterly winds starts to raise and transport dust particles from the Sahara Desert during the harmattan period usually occur in late November to February. This period is also referred to as dry season. There is a period of light precipitation or without precipitation with high humidity called locally as August Break' (Little Dry Season) usually experienced in the southwest which affects Lagos also. NIMET in annual Seasonal Rainfall Prediction (SRP) reports predicted that the strong tele-connection between El Nino phase of the End of Storm /Southern Oscillation (ENSO), El Nino phase to the cold phase known as La Nina and rain-bearing systems (ITD) decides the rain pattern over Nigeria, with much of the effect pronounced in Lagos. [11] in his own contribution claimed that LDS was associated to the stronger subsidence outflows from deep convective system located to the North of the location i.e., between $6^{0}$ and $8.5^{0} \mathrm{~N}$. [12] showed that the phenomenon is peculiar to a section of West Africa lying between $4^{0}$ and $9^{0} \mathrm{~N}$ and $7^{0} \mathrm{E}$ and $12^{\circ} \mathrm{W}$ and only Southwestern, Nigeria falls within the location. [13] predicted that currents from Gulf of Guinea and Benguela are responsible for the LDS rainfall amount and rainy days. The google map of Lagos is shown in fig. 1 . 


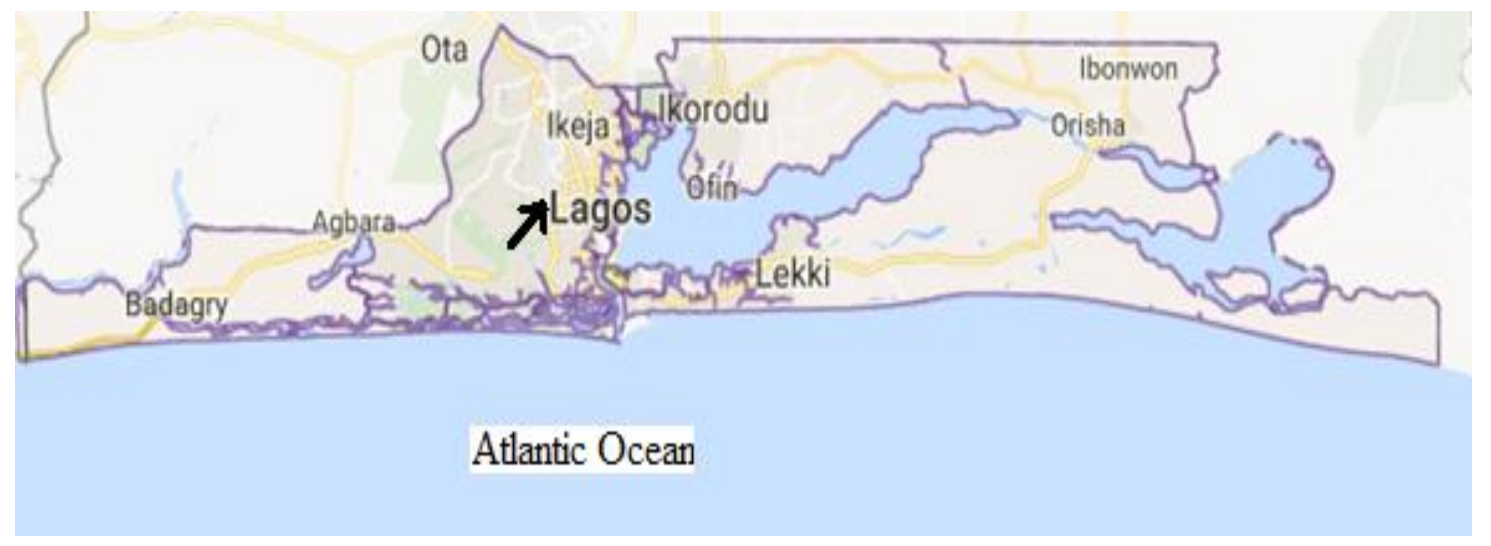

Fig 1. Google map of Lagos

\section{Theory of refractivity}

The reason for the refraction of the radio wave with respect to the height at regions above earth's surface is dielectric constant which varies with height. A typical numerical value of the dielectric constant for the vacuum is 1.0 but with the presence of water vapour the value increases and begin to decrease when the air density gradually reducing to very low value. The region or point where the dielectric constant of the troposphere decreases with height is referred to as normal refraction. At ground surface, the refractive index is given by

$$
n=\sqrt{\varepsilon} \approx 1.0003 \text {, }
$$

where $n$ is the refractive index, $\varepsilon$ is permittivity of the medium.

Due to insignificant value of decimal, the usual changes that occur in refractive index, a scaled-up approach are employed to make the insignificant decimal part meaningful. It is called radio refractivity denoted by $N$ given numerically as

$$
N=(n-1) \times 10^{6}
$$

and measured in $N$-units. According to Debye theory of polar molecules, refractivity can be calculated from temperature, $T$ and pressure $P$ as [1]

$$
N=\frac{77.6}{T}\left(P+4810 \frac{e}{T}\right)
$$

where $\mathrm{P}$ is the atmospheric pressure in millibars, $e$ is the water vapour pressure in millibars and is related to relative humidity $H$ in $\%$ by as 


$$
H=100 \frac{e}{e_{S}(T)},
$$

where $e_{S}(T)$ is a saturation vapour pressure and is dependent on absolute temperature, $T$ in $K$.

Water vapour is the most important constituent of the atmosphere and do experience a phase transition in the process of cooling. The thermodynamics of phase transitions is well described by Clausius-Clapeyron [2]. A well accepted version of the phase transition empirical relation in literature is Teten's formula given as [2]

$$
e_{s}=6.112 \exp \left(\frac{17.67 T\left({ }^{0} C\right)}{T\left({ }^{0} C\right)+243.5}\right)
$$

Rearranging equation (3), we obtain an approximated o

$$
N=77.6 \frac{P}{T}+3.75 \times 10^{5} \frac{e}{T^{2}} \quad \text { in } N \text {-units }
$$

Equation (6) may be split into dry term and wet term of the radio refractivity. The dry term, $N_{d r y}$ is given as

$$
N_{d r y}=77.6 \frac{P}{T} \text { and the wet term as } N_{w e t}=3.75 \times 10^{5} \frac{e}{T^{2}} \quad \text { in } N \text {-units }
$$

The dry term resulted from the non-polar nitrogen and oxygen molecules, and contributes about $70 \%$ of the total value. The wet term is from the polar water molecules. The constants are empirically determined, based on experimental measurements. $N$ is valid for frequencies between $100 \mathrm{MHz}$ to $80 \mathrm{MHz}$ [3], [14].

\section{Equipment and Methodology}

The data used in this study is obtained from NECOP (NECOP is an acronym for Nigerian Environmental and Climatic Observing Program). The NECOP equipment used for the study has been described in literature [6] and [8]. It is a piece of equipment designed to establish a network of meteorological and climatological observing stations in real time, through telemetry technology, with five minutes update cycles. Variables being generated from the Lagos $\left(06^{\circ} 52^{\circ} \mathrm{N}\right)$ station of NECOP include: Air temperature (Degree C), Relative humidity (\%), Precipitation 
$(\mathrm{mm})$, Atmospheric pressure (mbar), Wind speed $(\mathrm{m} / \mathrm{s})$, Direction $\left({ }^{\mathrm{O}} \mathrm{N}\right)$, Solar radiation $\left(\mathrm{W} / \mathrm{m}^{2}\right)$, Soil moisture $(\%)$, Soil temperature $\left({ }^{\mathrm{O}} \mathrm{C}\right)$ and Rain Rate $(\mathrm{mm} / \mathrm{min})$.

\section{Evaluation of Surface Radio Refractivity}

The data collected from this station were used to generate the diurnal graphs of surface refractivity of fig. 1 for all $15^{\text {th }}$ day of year. There is no special reason for choosing $15^{\text {th }}$ day but selected arbitrarily to capture the diurnal variation and to see the effect of seasonal variation after all, seasonal variation is a matter of at least months excepts the so called August break which coincidentally falls in rainy season.
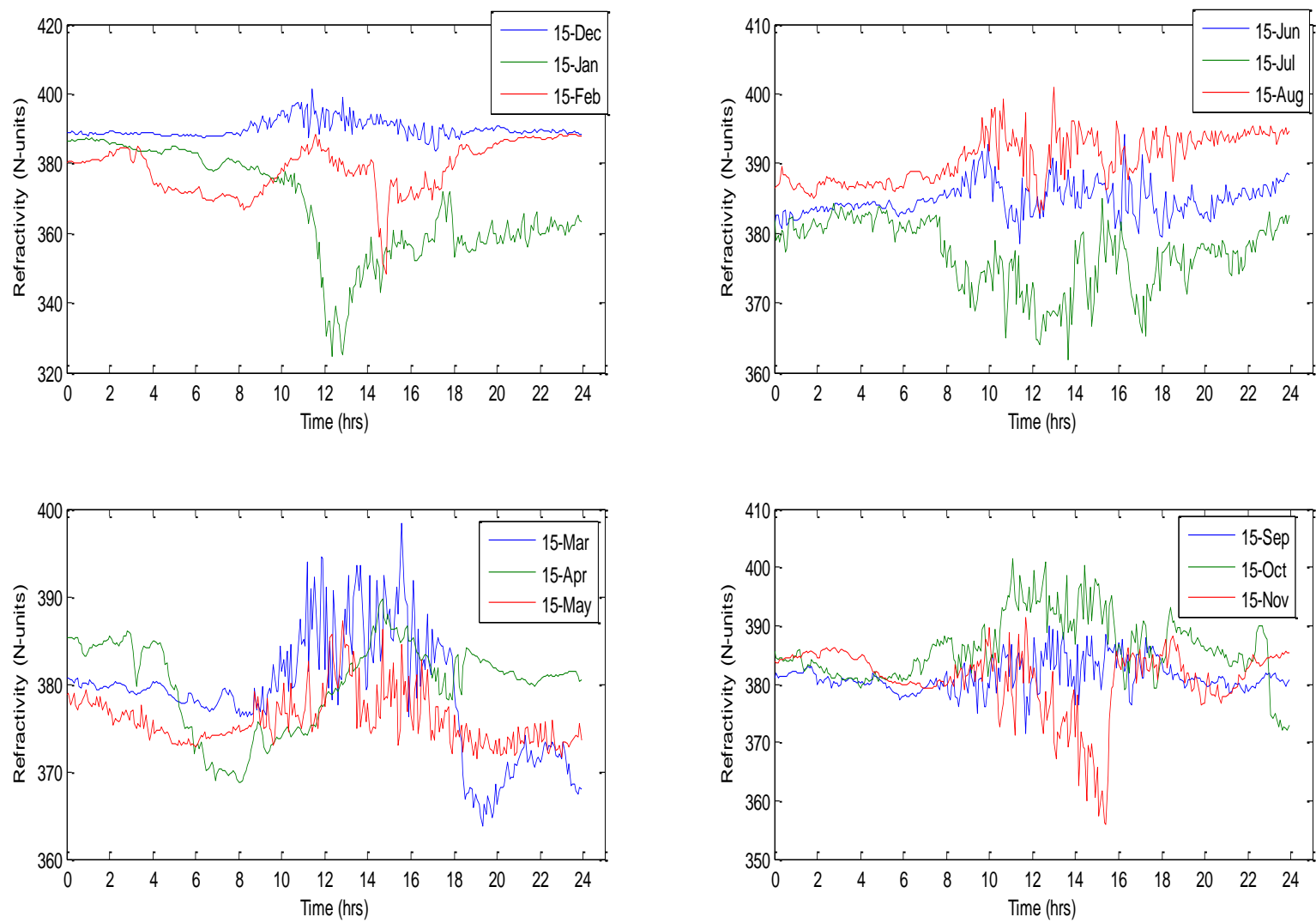

Fig. 2. Diurnal variation of surface refractivity versus time for selected days $\left(15^{\text {th }}\right.$ day of each month of the year).

\section{Results and Discussion}

Diurnal Variations of the surface Refractivity

Fig. 2 shows a diurnal variation of the surface refractivity at Lagos, a coastal area, which varies diurnally from $00 \mathrm{~h}$ to $23: 59 \mathrm{~h}$ local time daily are obtained from equations (5) and (7). All the selected days of the month of have similar pattern of 
profile, it decreases slowly from $00 \mathrm{~h}$ to about $08: 00 \mathrm{~h}$ local time before it starts to increase except the days selected from the months of December, August, June and July that is either slightly increase or remain almost constant throughout. This pattern is due to peculiar cloudy weather of emerging harmattan in December and the heavy rain associated with months of June and July. The month of August is known to be cloudy month with little or no rain popularly known as August break in the SouthWest region of Nigeria and resulted from the movement of the ITD. The value decreases sharply from 08:00h to about 13:00h when it has a minimum value and starts to pick up slightly around 14:00h to $15: 00 \mathrm{~h}$ for days selected in January, July and November and increases again, reaching a high value around 23:00h local time. All other days selected in each month of the year are with high values of refractivity throughout the day when sun is supposed to be shining.

The pattern of graphs can be attributed to the temperature and saturated vapour pressure of Lagos for its proximity to Atlantic Ocean and also surrounded with Lagoons. It is pertinent to note that the diurnal variations of the surface radio refractivity, $N_{S}$, at Lagos follows more closely the variation of water vapour pressure, $e$, than the variation of any other parameters. The most interesting features of the diurnal variations of $N_{S}$ is high values no matter the time of the days selected.

\section{Seasonal Variations of the Surface Radio Refractivity and other Meteorological Parameters}

The seasonal variation profiles of the three meteorological parameters (pressure, temperature and relative humidity) required for the computation and their corresponding profiles of the average real time variability patterns of the radio refractivity at every five minutes' interval for each month of the year for three years are shown in figures 3 to 8 . Though there are two seasons recognised, the dry season which extends from December to February have high temperature as seen from fig. 3, with a peak temperature of about $36^{\circ} \mathrm{C}$ followed by December with least temperature in January, this coincides with the peak of harmattan period when the northeasterly trade winds from Sahara Desert prevails. In the same vein, pressure is also high and highest numerical value of 1065 mbar is obtained in February but the relative 
humidity is fluctuating between about 20-95 \% from late January and through February. The corresponding profiles of monthly refractivity follows the pattern of relative humidity, i. e. is fluctuating with a wide range of about $150 \mathrm{~N}$-units $(280 \mathrm{~N}$ units to $430 \mathrm{~N}$-units) in January. The late February to early March coincides with the beginning of raining season, i. e. transition from dry season to raining season in Lagos. The raining season begins in March through to the cessation period in November, both the beginning and the ending is marked with high temperature as depicted in fig. 3 .
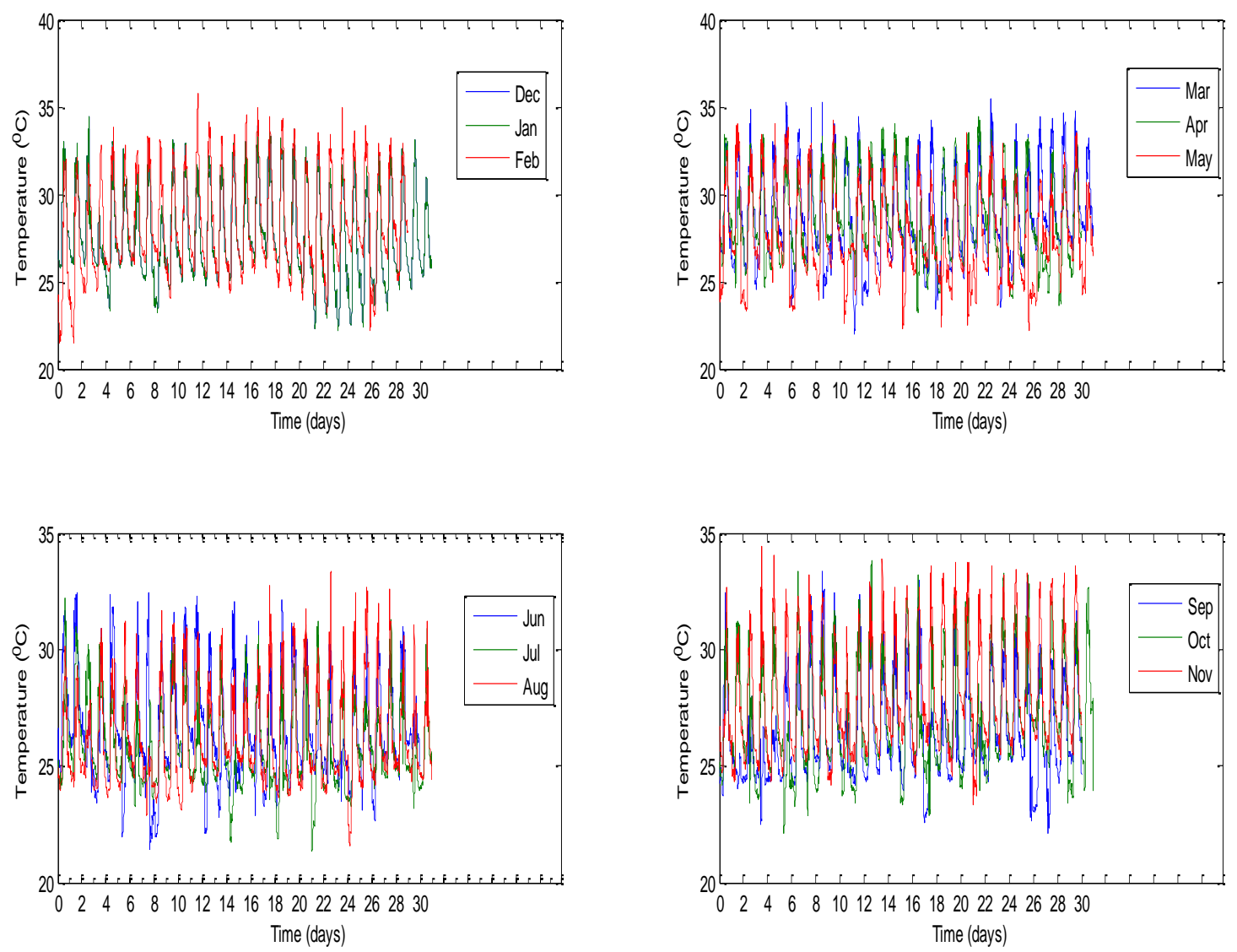

Fig. 3. Average monthly Temperature versus time for the three years (From November 2007 to October, 2010)

The pressure during the raining season is high in March (the beginning of the raining season), August, September and October. Unlike temperature, though it is high but not so high during the cessation period of the raining season in November. Almost all the months of raining season are associated with heavy downpour but May, June and July are peculiar with all round showering of rain throughout the period, this is 
evident in the high water vapour recorded during the period (fig.5). The so called August break in the South-West region caused the little drop in the refractivity in the month of August when comparing with July and June patterns because of shortfall in precipitation associated with that period. The temperature is seen to be low towards the end of July to middle August, the period of the little dry season also accompanying with high pressure but with low relative humidity compared with other raining months. The saturated water vapour pressure $e_{s}$, according to equation (5) relies solely on temperature, with the higher temperature, corresponding to higher saturated water vapour pressure. The value of saturated vapour pressure also relies on relative humidity according to equation (4).
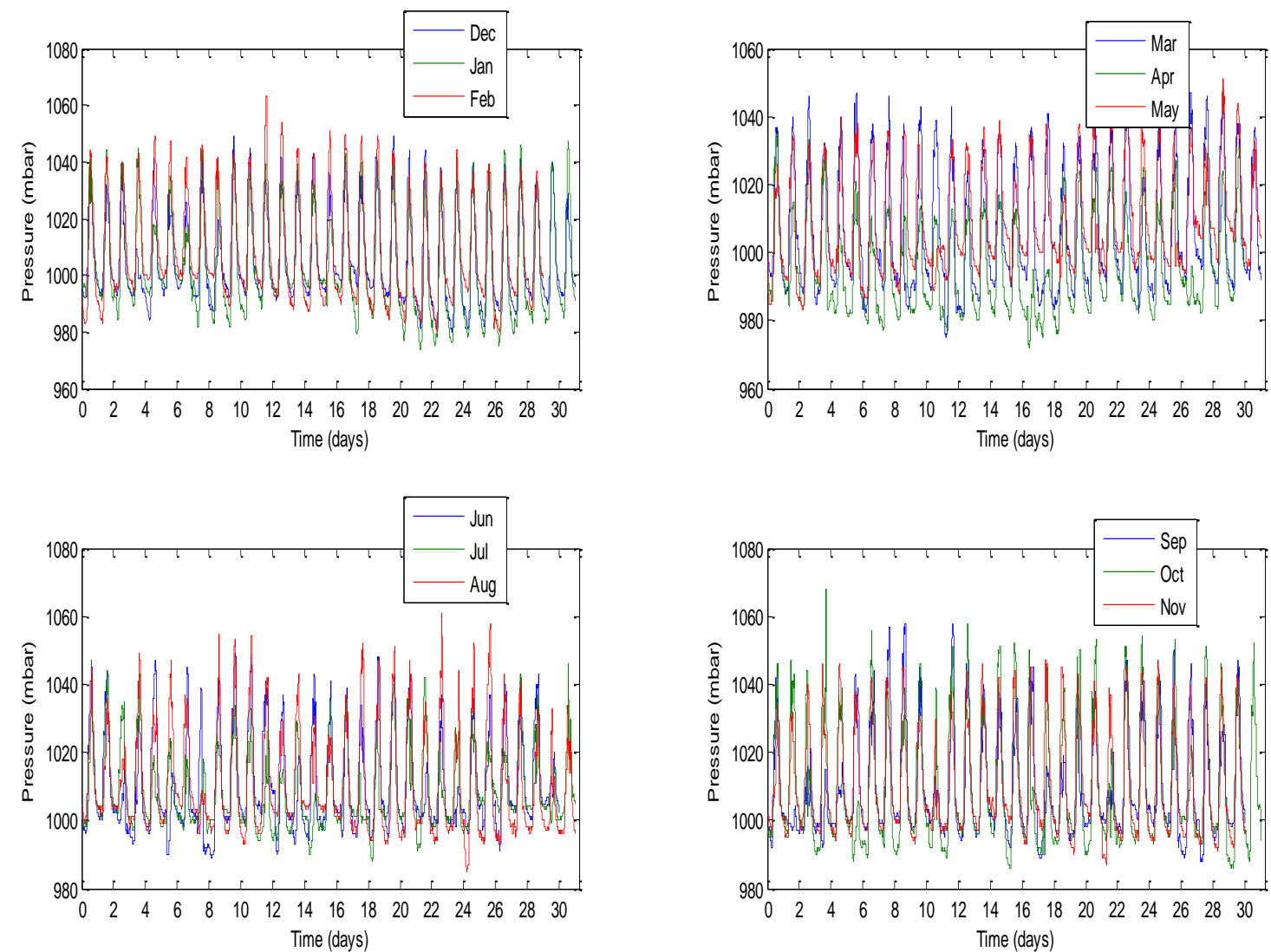

Fig. 4. Average monthly pressure versus time for the three years (November 2007 to October, 2010)

The seasonal and diurnal variations of the wet term have been observed to correlate with the variation of VHF and UHF field strengths in Southwest part of Nigeria [4]. This observation can be partly explained the low signal level often 
received in the afternoon period, especially from long distance transmitting stations, when the refractivity is minimum. It was also observed that the value of refractivity is low in January and increased sharply from January to February, from February there was a slight increase in refractivity till October when higher values of refractivity were recorded.
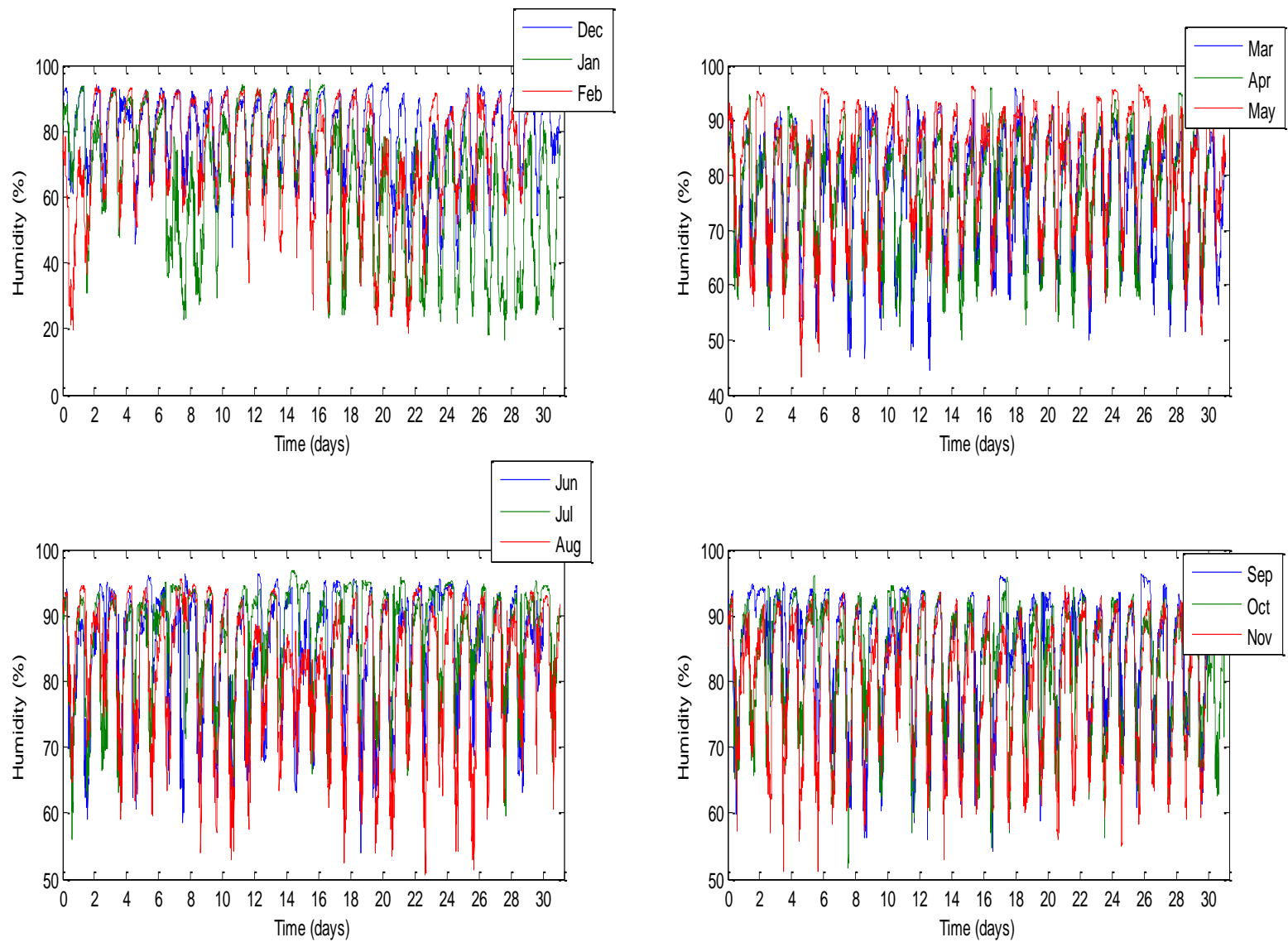

Fig. 5. Average diurnal relative humidity versus time for the three years (November 2007 to October, 2010)

This showed that the value of refractivity during the raining season is high and refractivity during the dry season is low. This is attributed to extensive cloud cover and saturation of the atmosphere with larger amount of water vapour during this period. The results show that seasonal variation is caused mainly by climatic conditions and the value of average seasonal surface radio refractivity is not less than $370 \mathrm{~N}$-units. The results show maximum value of about $386.69 \mathrm{~N}$-units in May and minimum in January and August. The peak of harmattan is January which coincides with dry season (December to February) and drop in August can be attributed to 
August break due to the sudden drop in the water vapour (humidity). Though there is no concrete evidence to this phenomenon but it has been attributed to ITD [15-18]. This result agrees with work of [6] and [4]. This pattern of variation can be attributed to rain pattern in Lagos over the period under study where it usually rain till November, and December in some years [19]. The diurnal refractivity variation is basically a function of local meteorology, while the seasonal variation is caused by the trend of climatic conditions [9] and [6].
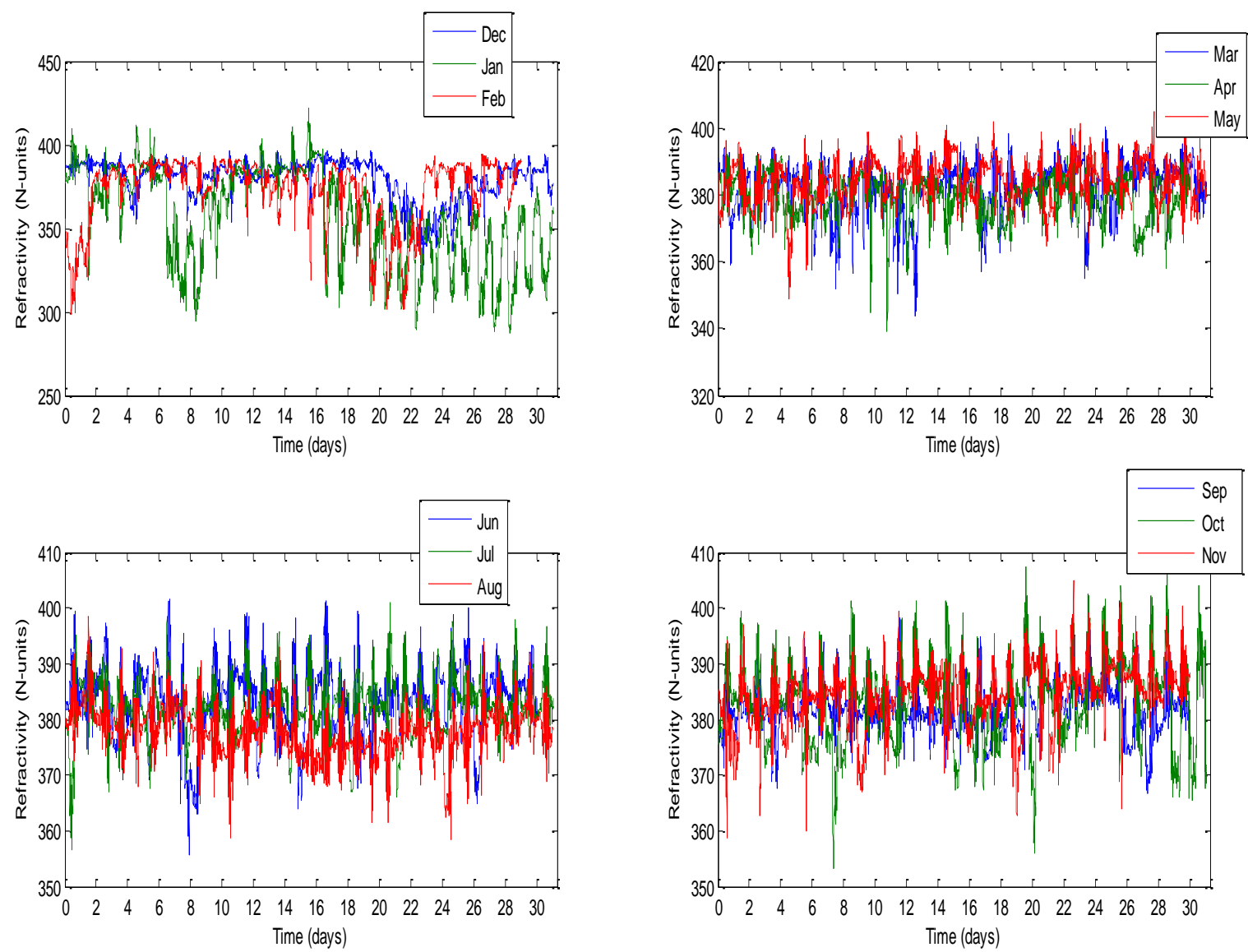

Fig. 6. Average monthly refractivity against time for the three years at a glance.

In this work, much emphases were laid on surface refractivity because lapse rate feedback amplifies troposphere due to surface warming which generate moist processes that usually enhance the warming at the troposphere than at the ground surface where it was originated. The amplification is more pronounced in the tropics due to the type of weather than in the high latitudes [2] and [20]. The tropical tropospheric temperatures and temperature variability are more geographically uniform than at the surface and cannot maintain substantial horizontal pressure and 
temperature gradients because of low local Coriolis parameter. The surface is only slightly affected by this parameter but rather shows a large variation in temperature due to complexity associated with the processes at the surface and atmospheric boundary layer above it. Therefore, from the data available, higher values of refractivity were obtained throughout the year even during the dry season, these values range between about $360 \mathrm{~N}$-units and $400 \mathrm{~N}$-units with highest values in October.
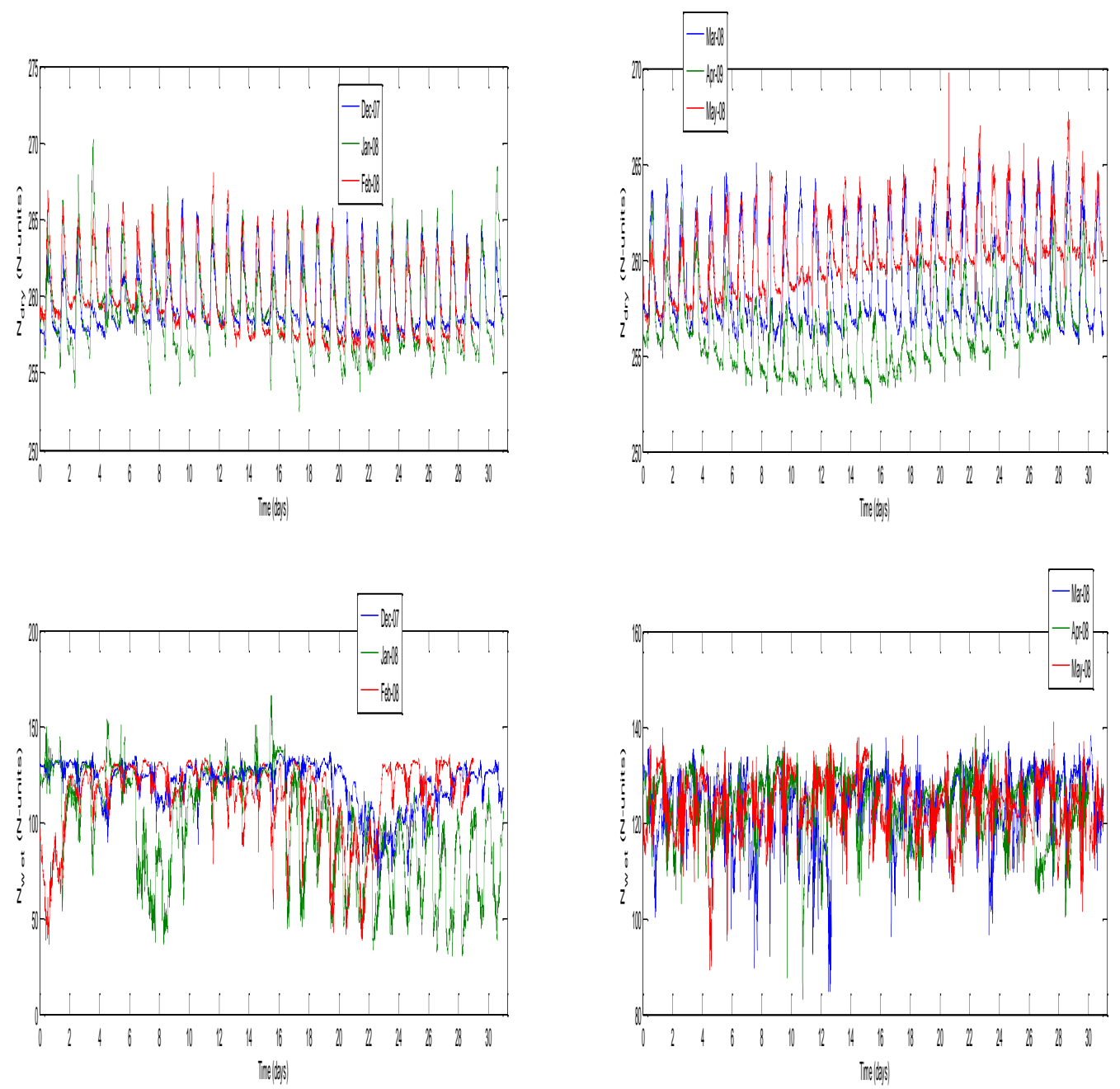

Fig. 7. Comparison between $N_{d r y}$ and $N_{\text {wet }}$ versus time for the months of December to May.

\section{Conclusion}

Lagos state belongs to coastal region of Nigeria and therefore characterised with rainfall through the year because of its proximity to the Atlantic Ocean. The study shows that the region is characterise by high refractivity almost through the 
year at both ground or surface and the profiles of the altitude of refractivity gradient are also high.
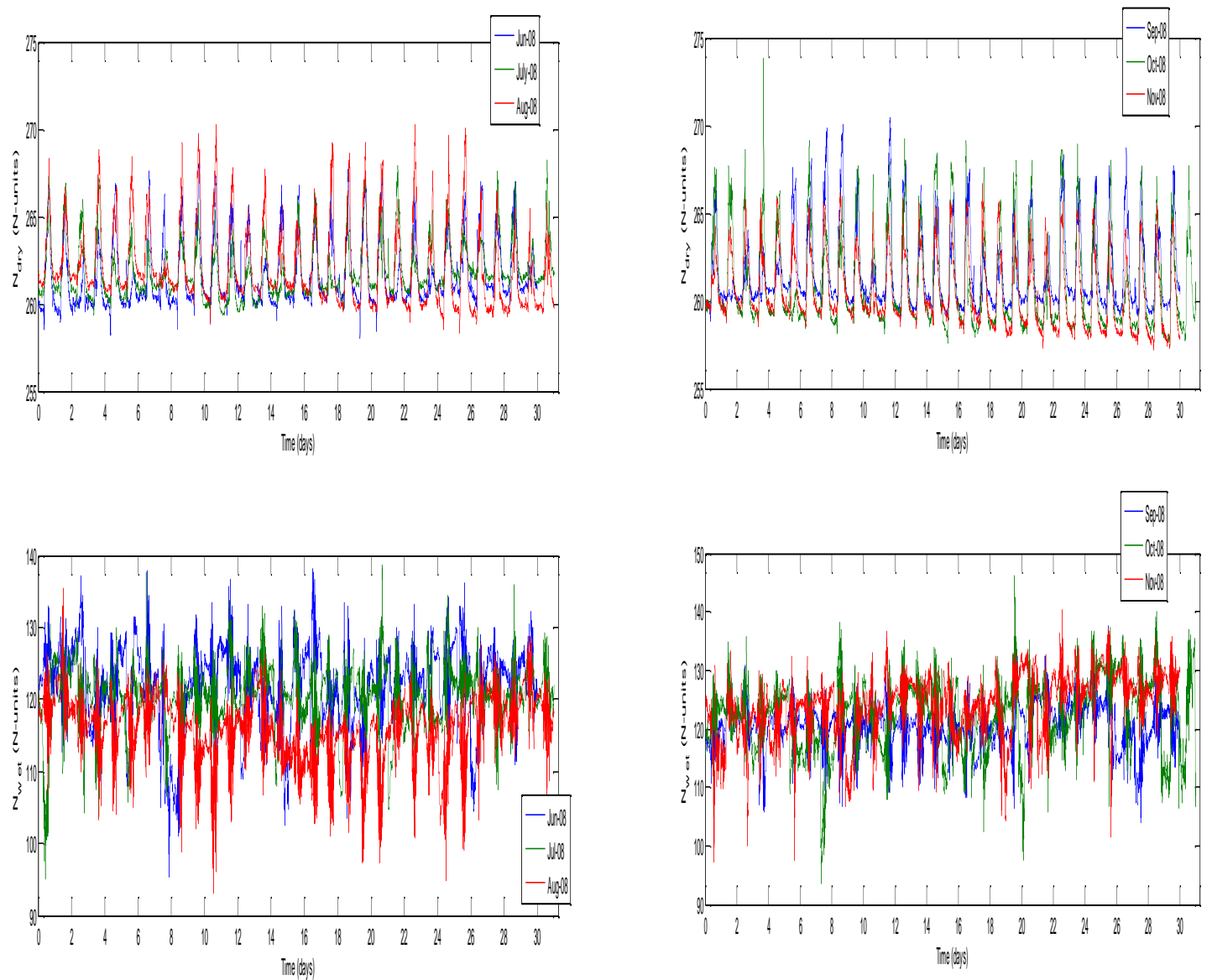

Fig. 8. Comparison between $N_{d r y}$ and versus time $N_{w e t}$ for the months of June to November.

The diurnal pattern of the surface radio refractive index during the dry and wet season for the three years (November 2007 to October 2010) have the same pattern of profile, therefore average values were used to compute the refractivity. It increases slowly from $00 \mathrm{~h}$ to around $08: 00 \mathrm{~h}$ local time before it starts to decrease. The rate of decrease is so low even in the afternoon when we should be expecting sharp drop. The diurnal variation of refractivity may be due to local weather conditions and topography. The seasonal pattern of surface refractivity distribution over Lagos, a coastal area, may be due to (in part to) the migration of the oscillatory movement of ITD, which largely dictates the weather pattern of Nigeria, and hence Lagos. This movement dictates and controls the rainfall, and hence the water vapour and 
refractivity profile throughout Nigeria. It was observed that surface radio refractivity followed the same trend almost throughout the year in this study except on few cases during the dry season. Values of surface radio refractivity at surface are high both in the wet season and dry season except in August with lower value of refractivity. This is due to high water vapour content of the atmosphere in Lagos. Finally, high values of refractivity is attributed to extensive cloud cover and saturation of the atmosphere with larger amount of water vapour through the year.

\section{References}

1. Hall, M.P. Effects of the troposphere on radio communication. IEE Electromagnetic Waves Series, United Kingdom, Peter Peregrinus Ltd, 1989, 105127.

2. Ambaum, M. H. P. Thermal Physics of the Atmosphere. Advancing weather and climate science. United States. Wiley-Blackwell, John Wiley \& Sons, 2010, 1- 239. 3. Bean, B.R. and Dutton, E. J. Radio Meteorology. New York, Dover publications, 1966, 1-435.

4. Owolabi, I. E. and Williams, V. A. Surface Radio Refractivity Pattern in Nigeria and Southern Cameroon, Journal of West African Science Association, 1970, Vol. 20, No.1, 3-17

5. Oyedum O.D. and Gambo G.K. Surface radio refractivity in northern Nigeria. Nigerian Journal of Physics, 1994, Vol. 6, 36-41.

6. Ayantunji, B. G., Okeke, P. N. and. Urama, J. O. Diurnal and Seasonal Variation of Surface Refractivity over Nigeria, Progress in Electromagnetics Research, 2011, Vol. 30, 201-222.

7. Falodun S. E., Okeke P. N. Radiowave propagation measurements in Nigeria (preliminary reports). Theoretical Applied Climatology, 2013, Vol. 113, 127-135. DOI: 10.1007/s00704-012-0766-z.

8. Falade, J. A., Adesanya, S. O. and Akinyemi G. A. Variability of meteorological factors on surface refractive index over Mowe, a coastal area in Nigeria. Indian Journal of Radio \& Space Physics, 2014, Vol. 43, 355-361. 
9. Willoughby A.A., Aro T. O., Owolabi I. E. Seasonal variations of radio refractivity gradients in Nigeria. Journal of Atmospheric and Solar-Terrestrial Physics, 2002, Vol. 64, No.4, 417-425.

10. Falodun S. E., Ajewole M. O. Radio refractive index in the lowest 100-m layer of the troposphere in Akure, South Western Nigeria. Journal of Atmospheric and SolarTerrestrial Physics, 2006, Vol. 68, No. 2, 236-243.

11. Omotosho J. B. Spatial variation of rainfall in Nigeria during the little dry season. Atmospheric Research, 1988, Vol. 22, No. 2, 137-147.

12. Adefolalu D.O. On the mean equivalent potential temperature of the tropical atmosphere and the "Little Dry Season" over West Africa. Nig. Quarterly Meteorology Magazine, 1972, Vol. 2, No. 1, 15-40.

13. Odekunle T. O. Predicting the variability and severity of the "Little Dry Season" in southwestern Nigeria. IFE Journal of Science, 2007, Vol. 9, No.1, 93-108.

14. ITU-R. The radio refractivity index: its formula and refractivity data, International Telecommunication Union, Geneva, 2012, 453-9.

15. Fontaine B., Janicot S., and Moron V. Rainfall anomaly patterns and winds field signals over West Africa in August (1958-1989). America Meteorological Society, 1994, Vol. 8, 1503-1510.

16. Hastenrath, S. and Lamb, P. On the dynamics and climatology of surface flow over the equatorial oceans. Tellus, 1978, Vol. 30, 436-448. Available at http://csep10.phys.utk.edu/astr161/lect/earth/atmosp here.html

17. Xian, P. And Miller R. L. Abrupt seasonal migration of the ITCZ into the summer Hemisphere. Journal Atmospheric Science, 2007, Vol. 65, 1878-1895. DOI: 10.1175/2007JA.

18. Chineke T. C., Jagtap S. S., and Nwofor O. West African monsoon: is the August break "breaking" in the eastern humid zone of Southern Nigeria? Climate change, 2010, Vol. 103, 555-570. DOI 10.1007/s10584-009-9780-2.

19. Nigerian Meteorological Report. Nigeria climate review bulletin (2010), pp.1-10. Available at http://www.nimetng.org 
20. Grist J. P., and Nicholson E. A study of the dynamic factors influencing the rainfall variability in the West African Sahel. Journal of Climate, 2001, vol. 14, No.7, 1337-1359.

\section{For citation:}

J. A. Falade, S. O. Adesanya. The Season and Diurnal Cycles of Surface Level Refractivity on Electromagnetic Wave Path in Lagos, Nigeria. Zhurnal Radioelektroniki - Journal of Radio Electronics. 2018. No. 7. Available at http://jre.cplire.ru/jre/jul18/7/text.pdf DOI $10.30898 / 1684-1719.2018 .7 .7$ 